\title{
Multiple Meningiomas in a Patient with Cowden Syndrome
}

\author{
Margaret Pain ${ }^{1}$ Armine Darbinyan ${ }^{2}$ Mary Fowkes ${ }^{2}$ Raj Shrivastava ${ }^{1}$ \\ ${ }^{1}$ Department of Neurosurgery, The Mount Sinai Hospital, New York, \\ New York, United States \\ 2 Department of Pathology, The Mount Sinai Hospital, New York, \\ New York, United States

\begin{abstract}
Address for correspondence Margaret Pain, MD, Department of Neurosurgery, The Mount Sinai Hospital, 1 Gustave L Levy Place, New York, NY, United States 10029 (e-mail: margaret.pain@mountsinai.org).
\end{abstract}

J Neurol Surg Rep 2016;77:e128-e133.

\begin{abstract}
Keywords

- Cowden syndrome

- PTEN

- meningioma

Background Cowden syndrome is a rare, multisystem disease manifesting with increased hamartomas and neoplasms. Though meningioma has been documented in patients with Cowden syndrome, the relationship between these two phenomena is still unclear.

Case Description We report a case of a 43-year-old female patient with a known PTEN mutation and clinical history of Cowden syndrome. A workup of headache demonstrated two skull base meningiomas. At the time of surgery, several additional tiny meningiomas were detected in the same region.

Conclusions The development of multiple meningiomas in a patient with predisposition for tumor is more than coincidental. Though PTEN mutations and deletions have not been shown to be critical for meningioma development, this case challenges that conclusion. In light of recent genetic advances in meningioma molecular pathogenesis, the role of the PTEN/AKT/PI3K pathway is discussed.
\end{abstract}

\section{Introduction}

Cowden syndrome (CS) is a rare autosomal dominant tumor syndrome first described in 1963 by Lloyd and Dennis. ${ }^{1}$ It is a unique multisystem genetic disease characterized by multiple hamartomas. Cowden syndrome has been most commonly linked to mutations and deletions of PTEN (phosphatase and tensin homologue). ${ }^{2-4}$ Other germline mutations found to be responsible for the phenotype include $S D H D, S D H B$, and KILLIN. The most common clinical manifestations include: frequent skin tags and polyps, breast papilloma, follicular thyroid cancer, and gastrointestinal tract hamartomas. To date, there has been no single genetic mutation linked to Cowden syndrome. It remains a clinical diagnosis based upon known constellation of objective findings. ${ }^{4}$

Even in the absence of a common mutation, most germline mutations associated with clinically diagnosed Cowden syndrome tend to involve activation and function of PTEN.
Overall, $80 \%$ of all the cases are related to PTEN mutations or deletions. ${ }^{2}$ Accounting for approximately $10 \%$ of all cases of Cowden syndrome, $S D H B$ and SDHD belong to the succinate dehydrogenase enzyme family. ${ }^{5}$ Mutations in these genes are thought to produce a Cowden syndrome phenotype by their effect on PTEN. When present, these mutations cause the protein to accumulate in the nucleus, causing a functional deficiency of PTEN in the cytoplasm. In contrast, changes in KILLIN expression relevant to Cowden syndrome are thought to be the result of hypermethylation of a promoter common to both KILLIN and PTEN. ${ }^{6}$ The effects of this change lead to failure to activate p53 proapoptotic pathways and PTEN expression and function is relatively unaffected.

The overall incidence of central nervous system neoplasms and hamartomas associated with Cowden syndrome is poorly characterized due to small series numbers but may be as high as $35 \%{ }^{7}$ Neurological features linked to Cowden syndrome include dysplastic gangliocytoma of the cerebellum received

November 11, 2015 accepted after revision April 2, 2016
DOI http://dx.doi.org/ 10.1055/s-0036-1584265. ISSN 2193-6358. (c) 2016 Georg Thieme Verlag KG Stuttgart · New York
License terms

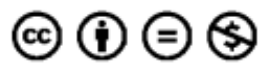


(Lhermitte-Duclos disease), macrocephaly, autism spectrum disorder, and intracranial vascular abnormalities. ${ }^{4,7}$ Lhermitte-Duclos disease has the most commonly documented association with Cowden syndrome but the role of PTEN in its etiology is still unclear.

In this report, we describe a case of multiple meningiomas with brain invasion in a patient with Cowden syndrome. The development of multiple tumors of the same cell origin in the setting of a germline mutation strengthens the argument of a relationship between the PTEN/AKT/PI3K pathway and meningioma tumorigenesis.

\section{Case History}

\section{Presentation}

The patient is a 43-year-old female with a medical history significant for multiple breast papillomas, follicular thyroid carcinoma (with resection and postoperative radiation therapy), gastric and colon polyps, innumerous skin tags, and metabolic syndrome. In response to her history of multiple primary neoplasms, she was referred to medical genetics and found to be a heterozygote for the $R 335 \mathrm{X}$ mutation in exon 8 of PTEN and ultimately diagnosed with Cowden syndrome. One year before presentation in neurosurgery clinic, she had sought medical attention for new-onset severe headache with retroorbital pain. Workup of this complaint demonstrated two dural-based lesions superior to the left orbital roof that increased in size over a period of 12 months (-Fig. 1A).

\section{Examination}

On presentation, the patient was noted to be obese, but well appearing with numerous skin tags and nodules throughout her scalp, neck, and extremities. Her visual acuity in the right
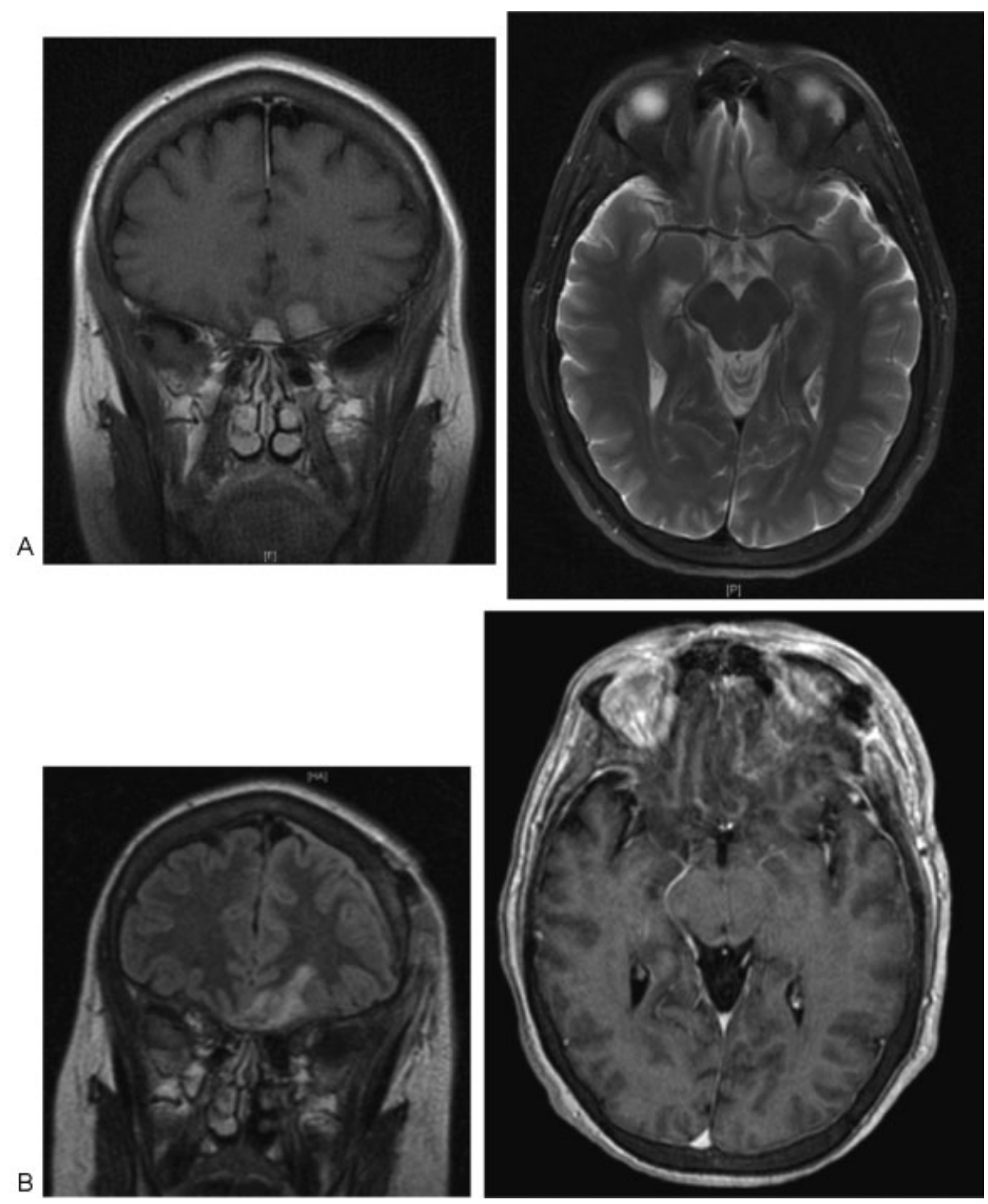

Fig. 1 (A) Preoperative MRI demonstrating interval growth from prior studies (not shown). Two skull base meningiomas identified. (B) Postoperative MRI. T2-FLAIR coronal sections and T1-postcontrast axial sections demonstrate gross total resection of the previously noted lesions. FLAIR, fluid-attenuated inversion recovery; MRI, magnetic resonance imaging. 
eye was 20/30 and 20/50 in the left. Visual fields were grossly full to confrontation. She was otherwise neurologically intact.

\section{Surgical Procedure}

The enlarging subfrontal paraoptic lesions were removed via a left orbitofrontal approach. The larger of the two lesions was encountered almost immediately upon exposure and removed en bloc. Exploration of the anterior fossa and external cavernous sinus revealed multiple small neoplasms, consistent in appearance with meningioma. One lesion was in direct contact with the left optic nerve and was causing compression. For several of the lesions, the border between the brain and tumor was indistinct. In total, five separate lesions were removed with no evidence of additional or residual tumor.

\section{Pathology}

Microscopically, the pathological diagnosis was meningioma. Sections demonstrated a moderately cellular tumor composed of a monomorphic population of meningothelial tumor cells forming whorls and lobules ( - Fig. 2). The cells had ovoid nuclei with regular contours, eosinophilic cytoplasm, with rare nuclear pseudoinclusions but numerous psammoma bodies. Few mitotic figures were observed. However, in contrast to these benign findings, adherent brain parenchyma was also found. Sections of these areas demonstrated islands of tumor cells surrounded by gliotic brain parenchyma, which was consistent with brain invasion. The tumor was eventually given the category of the World Health Organization (WHO) grade II with brain invasion.

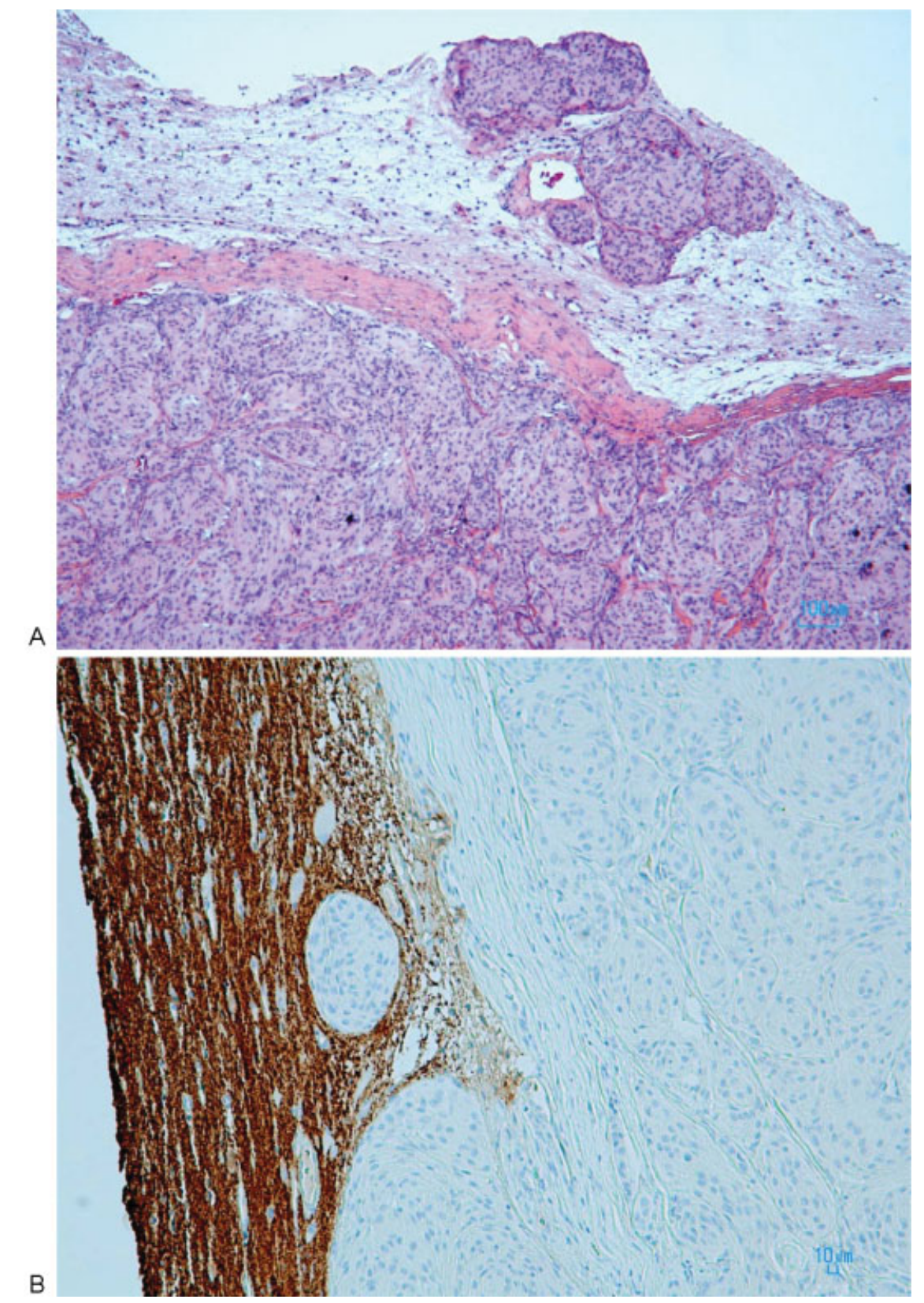

Fig. 2 (A) H\&E stain of meningioma, demonstrating focal brain invasion. (B) Synaptophysin stain of meningioma specimen. Focal brain invasion is demonstrated. H\&E, hematoxylin and eosin. 


\section{Postoperative Course}

Clinically, the patient tolerated surgery well and the visual acuity of her left eye improved to 20/25. A postoperative magnetic resonance imaging obtained at 3 months after surgery demonstrated complete resection of the lesions (-Fig. 1B). Additionally, no new lesions were identified. Given the multiplicity of the tumors, regular follow-up imaging is planned.

\section{Discussion}

The clinical manifestation of Cowden syndrome continues to evolve as the complex genetic relationships underlying its manifestations are clarified. In this case report, we describe a unique presentation of Cowden syndrome with multiple meningiomas with atypical features. The genetic implications of these findings raise questions not only about Cowden syndrome, but about the genetic basis of meningioma pathogenesis as well.

\section{Genetic}

As a mediator of cell cycle arrest and apoptosis, PTEN has been shown to play a critical role in tumorigenesis and suppression. ${ }^{8}$ PTEN is a lipid and protein phosphatase with varied roles in cell cycle regulation and DNA repair that appear to be dependent on molecular microenvironment. ${ }^{8}$ Classically, tumor susceptibility was thought to be a consequence of aberrant regulation of the AKT/PI3K pathway in the cell cytoplasm. $^{8-10}$ Insufficient or dysfunctional PTEN provides poor feedback inhibition of AKT and leads to dominance of kinase function and cell cycle overdrive. ${ }^{8}$ Linkage analysis of five families demonstrating Cowden syndrome heritance revealed mutations of $10 \mathrm{q} 23$, the locus for the PTEN gene. ${ }^{2}$ PTEN appears to play an important role in the development of other primary central nervous system tumors. In glioblastoma, PTEN mutations portend a poor prognosis. ${ }^{9,11}$ In glial tumors of the same grade, those patients harboring PTEN mutations have a significantly shorter overall survival than their counterparts without such mutations. ${ }^{12}$

The role of PTEN in meningioma pathogenesis is less clear. Atypia and anaplasia in meningioma have been associated with loss of heterozygosity at $1 \mathrm{p}, 10 \mathrm{q}$, and $14 \mathrm{q} .{ }^{13}$ Although the PTEN gene maps to chromosome subband 10q23.3, no specific linkage of PTEN to tumor development has been found. PTEN loss of heterozygosity has been noted with increased frequency in histologically malignant tumors but a causal relationship was not demonstrated. ${ }^{14,15}$ While there is little evidence to suggest that it plays a significant role in the etiology of WHO grade I tumors, several studies have suggested that it plays a role in the development of a subset of higher grade tumors. ${ }^{15}$

Table 1 Reported cases of meningioma in Cowden syndrome

\begin{tabular}{|c|c|c|c|c|}
\hline Reference & Age/gender & CNS lesions & Location & Treatment \\
\hline Weary et al, $1972^{20}$ & $27 / \mathrm{M}$ & Meningioma & $\begin{array}{l}\mathrm{R} \text { acoustic/external } \\
\text { auditory canal }\end{array}$ & Surgery $\times 2$ \\
\hline Fritsch et al, $1981^{22}$ & $59 / F$ & Meningioma & Unavailable & Unavailable \\
\hline Lyons et al, $1993^{23}$ & $41 / F$ & Meningioma & $\begin{array}{l}\text { Parasellar/cavernous } \\
\text { sinus }\end{array}$ & Biopsy and radiation \\
\hline Rimbau and Isamat, $1994^{24}$ & $31 / \mathrm{F}$ & $\begin{array}{l}\text { Meningioma; dysplastic } \\
\text { gangliocytoma }\end{array}$ & $\begin{array}{l}\text { Meningioma: right } \\
\text { frontal convexity } \\
\text { DGC: cerebellum }\end{array}$ & $\begin{array}{l}\text { Meningioma: surgery } \\
\text { DGC: surgery }\end{array}$ \\
\hline Lindboe et al, $1995^{25}$ & $43 / \mathrm{M}$ & $\begin{array}{l}\text { Atypical meningioma; } \\
\text { dysplastic gangliocytoma }\end{array}$ & $\begin{array}{l}\text { Meningioma: right } \\
\text { frontoparietal convexity } \\
\text { DGC: cerebellum }\end{array}$ & $\begin{array}{l}\text { Meningioma: surgery } \\
\text { and radiation } \\
\text { DGC: surgery }\end{array}$ \\
\hline Staal et al, $2002^{26}$ & $42 / M$ & $\begin{array}{l}\text { Meningioma; anaplastic } \\
\text { oligodendroglioma }\end{array}$ & $\begin{array}{l}\text { Meningioma: right } \\
\text { frontal } \\
\text { AO: left frontal }\end{array}$ & $\begin{array}{l}\text { Meningioma: surgery } \\
\text { AO: surgery } \times 2 \text {, } \\
\text { radiation }\end{array}$ \\
\hline Rademaker et al, $2005^{27}$ & $25 / \mathrm{F}$ & Meningioma & Unavailable & Unavailable \\
\hline Lok et al, $2005^{7}$ & $50 / \mathrm{M}$ & Meningioma & Left convexity/insula & Unavailable \\
\hline Isobe et al, $2005^{28}$ & $57 / F$ & $\begin{array}{l}\text { Atypical meningioma; } \\
\text { dysplastic gangliocytoma }\end{array}$ & $\begin{array}{l}\text { Meningioma: left frontal } \\
\text { DGC: cerebellum }\end{array}$ & Meningioma: surgery \\
\hline Vasovčák et al, $2011^{29}$ & $49 / \mathrm{F}$ & Meningioma & Left frontal & Surgery $\times 3$ \\
\hline Walsh et al, $2011^{30}$ & $34 / F$ & $\begin{array}{l}\text { Meningioma, dysplastic } \\
\text { gangliocytoma }\end{array}$ & $\begin{array}{l}\text { Meningioma: left } \\
\text { sphenoid wing } \\
\text { DGC: cerebellum }\end{array}$ & Observation \\
\hline
\end{tabular}

Abbreviations: AO, anaplastic oligodendroglioma; CNS, central nervous system; DGC, dysplastic gangliocytoma.

Note: A referenced list of all cases of Cowden syndrome with concomitant meningioma is shown in the table. Specific details about the pathology, location, and treatment were not provided in all cases. 
Interestingly, the exact role that the protein PTEN plays in these higher grade tumors is still poorly understood and may be related to the function of PTEN in the nucleus. ${ }^{8,16}$

Recent work in the field of meningioma genomics has uncovered several driver mutations of low-grade tumors and demonstrated interesting linkage between the mutation and tumor location. ${ }^{17}$ AKT1 mutations with associated activation of the AKT/PI3K pathway were discovered in a significant number of meningiomas. ${ }^{17,18}$ Many of these tumors were not associated with NF2 mutations and they generally localized to the midline anterior fossa, planum sphenoidale, and clivus. ${ }^{17}$ AKT1 mutations were found in low- and high-grade tumors, and so the significance of this mutation as a forbearer of malignancy is unclear. ${ }^{17,19}$

While there have been reports of Cowden syndrome patients with meningioma, it is uncommon to observe multiple tumors of the same cell line in close proximity (see - Table 1). In spite of their rarity, there are some trends that emerge when reviewing the literature of these cases. The demographic had a lower predominance of females than typical meningiomas and patients tended to be younger at presentation. A higher percentage of patients were males than typically observed with meningioma and patients tended to be younger at presentation. Coincident dysplastic gangliocytoma was also frequently observed.

Meningiomas represent a heterogeneous group of tumors with a diverse array of underlying mutations. Historically, it has been difficult to separate which mutations drive tumor development from those occurring by chance. PTEN deletion has not been associated as a significant factor in meningioma development but recent work has highlighted the potential importance of PTEN/AKT/PI3K pathway in a subset of tumors. ${ }^{19}$ Perhaps, in the setting of inherent dysfunction of this pathway as in Cowden syndrome, multiple distinct tumors around the planum sphenoidale could be expected. However, the impact of this pathway upregulation on tumor atypia and recurrence is still unclear.

This case is of clinical interest because it fits within our current understanding of meningioma genetics, but also introduces several important questions. First, if we accept that patients with Cowden syndrome develop meningiomas with increased frequency, do these tumors only arise from specific locations in the skull? This would be most concordant with the theory that driver mutation influences tumor location and that PTEN loss of heterozygosity is important for tumor development. Second, does the frequency of recurrent meningioma in Cowden syndrome reflect an increased likelihood of malignancy or does it simply represent a predisposition for tumor development? Finally, what is the role of radiation and chemotherapy in these patients? Dedicated study of Cowden syndrome may enhance our understanding of meningioma development and treatment due to a common mutagenic pathway.

\section{References}

1 Lloyd KM II, Dennis M. Cowden's disease. A possible new symptom complex with multiple system involvement. Ann Intern Med 1963;58:136-142
2 Liaw D, Marsh DJ, Li J, et al. Germline mutations of the PTEN gene in Cowden disease, an inherited breast and thyroid cancer syndrome. Nat Genet 1997;16(1):64-67

3 Nelen MR, van Staveren WC, Peeters EA, et al. Germline mutations in the PTEN/MMAC1 gene in patients with Cowden disease. Hum Mol Genet 1997;6(8):1383-1387

4 Pilarski R, Burt R, Kohlman W, Pho L, Shannon KM, Swisher E. Cowden syndrome and the PTEN hamartoma tumor syndrome: systematic review and revised diagnostic criteria. J Natl Cancer Inst 2013;105(21):1607-1616

5 Yu W, He X, Ni Y, Ngeow J, Eng C. Cowden syndrome-associated germline SDHD variants alter PTEN nuclear translocation through SRC-induced PTEN oxidation. Hum Mol Genet 2015;24(1): 142-153

6 Bennett KL, Mester J, Eng C. Germline epigenetic regulation of KILLIN in Cowden and Cowden-like syndrome. JAMA 2010; 304(24):2724-2731

7 Lok C, Viseux V, Avril MF, et al; Cancerology Group of the French Society of Dermatology. Brain magnetic resonance imaging in patients with Cowden syndrome. Medicine (Baltimore) 2005; 84(2):129-136

8 Song MS, Salmena L, Pandolfi PP. The functions and regulation of the PTEN tumour suppressor. Nat Rev Mol Cell Biol 2012;13(5): 283-296

9 Chung JH, Eng C. Nuclear-cytoplasmic partitioning of phosphatase and tensin homologue deleted on chromosome 10 (PTEN) differentially regulates the cell cycle and apoptosis. Cancer Res 2005; 65(18):8096-8100

10 Gimm O, Perren A, Weng LP, et al. Differential nuclear and cytoplasmic expression of PTEN in normal thyroid tissue, and benign and malignant epithelial thyroid tumors. Am J Pathol 2000; 156(5):1693-1700

11 Arslantas A, Artan S, Oner U, et al. The importance of genomic copy number changes in the prognosis of glioblastoma multiforme. Neurosurg Rev 2004;27(1):58-64

12 Rasheed A, Herndon JE, Stenzel TT, et al. Molecular markers of prognosis in astrocytic tumors. Cancer 2002;94(10):2688-2697

13 Choy W, Kim W, Nagasawa D, et al. The molecular genetics and tumor pathogenesis of meningiomas and the future directions of meningioma treatments. Neurosurg Focus 2011;30(5):E6

14 Peters N, Wellenreuther R, Rollbrocker B, et al. Analysis of the PTEN gene in human meningiomas. Neuropathol Appl Neurobiol 1998; 24(1):3-8

15 Miller R Jr, DeCandio ML, Dixon-Mah Y, et al. Molecular Targets and Treatment of Meningioma. J Neurol Neurosurg 2014;1(1):

16 Terzi A, Saglam EA, Barak A, Soylemezoglu F. The significance of immunohistochemical expression of Ki-67, p53, p21, and p16 in meningiomas tissue arrays. Pathol Res Pract 2008;204(5):305-314

17 Clark VE, Erson-Omay EZ, Serin A, et al. Genomic analysis of nonNF2 meningiomas reveals mutations in TRAF7, KLF4, AKT1, and SMO. Science 2013;339(6123):1077-1080

18 Brastianos PK, Horowitz PM, Santagata S, et al. Genomic sequencing of meningiomas identifies oncogenic SMO and AKT1 mutations. Nat Genet 2013;45(3):285-289

19 El-Habr EA, Levidou G, Trigka EA, et al. Complex interactions between the components of the PI3K/AKT/mTOR pathway, and with components of MAPK, JAK/STAT and Notch-1 pathways, indicate their involvement in meningioma development. Virchows Arch 2014;465(4):473-485

20 Weary PE, Gorlin RJ, Gentry WC Jr, Comer JE, Greer KE. Multiple hamartoma syndrome (Cowden's disease). Arch Dermatol 1972; 106(5):682-690

21 Starink TM. Cowden's disease: analysis of fourteen new cases. J Am Acad Dermatol 1984;11(6):1127-1141

22 Fritsch P, Pechlaner R, Czarnecki N, Hintner H. [The multiple hamartoma syndrome (Cowden syndrome)]. Hautarzt 1981; 32(6):285-291 
23 Lyons CJ, Wilson CB, Horton JC. Association between meningioma and Cowden's disease. Neurology 1993;43(7): 1436-1437

24 Rimbau J, Isamat F. Dysplastic gangliocytoma of the cerebellum (Lhermitte-Duclos disease) and its relation to the multiple hamartoma syndrome (Cowden disease). J Neurooncol 1994;18(3): 191-197

25 Lindboe CF, Helseth E, Myhr G. Lhermitte-Duclos disease and giant meningioma as manifestations of Cowden's disease. Clin Neuropathol 1995;14(6):327-330

26 Staal FJ, van der Luijt RB, Baert MR, et al. A novel germline mutation of PTEN associated with brain tumours of multiple lineages. $\mathrm{Br} \mathrm{J}$ Cancer 2002;86(10):1586-1591
27 Rademaker J, Kim YJ, Leibecke T, Raman SS, Voit C. Cowden disease: CT findings in three patients. Abdom Imaging 2005; 30(2):204-207

28 Isobe N, Oki S, Murakami T, Ooyama S, Kureshima M, Kurokawa Y. [A case of atypical meningioma with Lhermitte-Duclos disease]. No Shinkei Geka 2005;33(12):1229-1235

29 Vasovčák P, Senkeříková M, Hatlová J, Křepelová A. Multiple primary malignancies and subtle mucocutaneous lesions associated with a novel PTEN gene mutation in a patient with Cowden syndrome: case report. BMC Med Genet 2011;12:38

30 Walsh S, Carter M, Tubridy N, McDermott EW. Lhermitte-Duclos and Cowden diseases: breast cancer as an unusual initial presentation of these overlapping conditions. BMJ Case Rep 2011;2011; 